\title{
Aging Clinical and Experimental Research changes the Publisher from 2013
}

\author{
Stefania Maggi
}

Received: 7 March 2013/Published online: 27 March 2013

(C) Springer International Publishing Switzerland 2013

As we begin the $25^{\text {th }}$ volume of Aging Clinical and Experimental Research, formerly published by Editrice Kurtis, it is my pleasure to welcome our new collaboration with Springer Science and Business Media.

Springer and the Italian Society of Gerontology and Geriatrics (SIGG) have agreed on a five-year partnership to publish Aging Clinical and Experimental Research, the official journal of the Society, on a bimonthly basis. I am very grateful to the President, Prof. Giuseppe Paolisso, and to the Board of Directors of the SIGG for their efforts to support the journal, not only economically at a time of financial constraints, but also through excellent scientific contributions and with invaluable suggestions and interactions with the editorial office.

The journal will be available as e-only publication on Springer's platform currently known as SpringerLink (http://www.link.springer.com) which provides access to more than 2,750 journals and more than 89,000 e-books. Full text articles will be made freely available to any subscriber and for the members of the Italian Society of Geriatrics and Gerontology.

Through Springer's international consortia reach, contents of our journal will be made available to more than 8,000 institutions offering worldwide visibility to Authors and contents.

I must confess that switching from print to electronic representing an important innovation and a relevant change for us, but we all know that it is an inescapable one. I feel comfortable in making this affirmation because I know that
I can count on the continuous efforts and outstanding academic excellence of the Editorial Board members and of all of our referees. I sincerely appreciate their willingness to serve in this role, and I am counting on their insight and expertise as they review manuscripts encompassing all aspects of aging research. I know, moreover, that I can count on the constant support of Professor Gaetano Crepaldi, who has just stepped down from the office of Editorin-Chief after 23 years of leadership but who will continue to collaborate in his new capacity as Emeritus Editor. The journal and editorial team have benefited enormously from his energy and managerial capability as well as his academic judgment and he will continue to be instrumental in our future activities.

Finally, to our authors, to best serve your needs, we recently introduced Editorial Manager, the electronic submission, and peer review system, which offers accurate reporting system and permits manuscript tracking through the whole review process until acceptance, minimizing time from receipt of the submitted article to final acceptance. This system will provide easier communications among Authors, Editorial Office, and Springer.

I hope that you will continue to submit your works to Aging Clinical and Experimental Research now that you know that Springer will lead to the journal's wider access, larger readership, and continued quality.

Conflict of interest None.

S. Maggi (两)

CNR Aging Branch, Institute of Neuroscience,

Via Giustiniani 2, 35128 Padua, Italy

e-mail: aging@unipd.it 